American Journal of Pharmaceutical Education 2016; 80 (9) Article 148.

\title{
RESEARCH
}

\section{Impact of the Birkman Method Assessment on Pharmacy Student Self-Confidence, Self-Perceptions, and Self-Awareness}

\author{
Whitney D. Maxwell, PharmD, MBA, ${ }^{a}$ Amy D. Grant, PharmD, MBA, ${ }^{a}$ Patricia H. Fabel, PharmD, ${ }^{a}$ \\ Cathy Worrall, PharmD, ${ }^{a}$ Kristy Brittain, PharmD, ${ }^{a}$ Breanne Martinez, PharmD, ${ }^{b}$ Z. Kevin Lu, PhD, ${ }^{a}$ \\ Robert Davis, PharmD, ${ }^{\mathrm{a}}$ Georgia H. Doran, BS, MEd, ${ }^{\mathrm{c}}$ Bryan Ziegler, PharmD, MBA ${ }^{\mathrm{a}}$ \\ ${ }^{\text {a }}$ South Carolina College of Pharmacy, South Carolina \\ ${ }^{\mathrm{b}}$ Saint Joseph East Hospital, Lexington, Kentucky \\ ${ }^{\mathrm{c}}$ University of South Carolina Darla Moore School of Business, Columbia, South Carolina \\ Submitted August 1, 2015; accepted February 8, 2016; published November 25, 2016.
}

Objective. To identify changes in pharmacy student self-confidence, self-perceptions, and self-awareness after completing the Birkman Method assessment and training program.

Methods. Survey tools were developed to evaluate students at baseline and following the co-curricular Birkman Method program. Following IRB approval, students participating in the Birkman Method program were recruited for enrollment in this survey-based study.

Results. Student self-confidence was high at baseline (mean $=4$ out of 5 ) and did not significantly change after Birkman Method testing and training. Self-perceptions regarding usual and stressed communication style and behaviors and behavioral needs under stress changed significantly after Birkman Method testing and training for these endpoints. The Birkman Method intervention resulted in a significant improvement in self-awareness, as indicated by a mean self-perception accuracy score increase of 1.6 points (95\% CI: $1.3-1.9$ ).

Conclusions. A Birkman Method assessment and training program is an effective self-assessment tool for students, and may be useful for accomplishing Accreditation Council for Pharmacy Education (ACPE) 2016 Standard 4 affective domain elements, particularly self-awareness.

Keywords: Birkman Method, self-awareness, self-perception, self-confidence, professional development

\section{INTRODUCTION}

The emphasis on self-awareness in the Accreditation Council for Pharmacy Education (ACPE) Standards is increasing. Self-awareness is now listed as a key element of Standard 4: Personal and Professional Development in the 2016 Accreditation Standards. According to Standard 4, the doctor of pharmacy (PharmD) graduate must be, “. . . able to examine and reflect on personal knowledge, skills, abilities, beliefs, biases, motivation, and emotions that could enhance or limit personal and professional growth". ${ }^{1}$ Self-awareness has been identified as an important component of emotional intelligence, ${ }^{2-5}$ effective interprofessional patient care, ${ }^{2,5}$ professionalism, ${ }^{5}$ self-efficacy, ${ }^{5}$ professional development, ${ }^{6}$ and cultural competence ${ }^{6}$ across a variety of healthcare

\section{Corresponding Author: Whitney D. Maxwell, South}

Carolina College of Pharmacy - USC Campus, Department of Clinical Pharmacy and Outcomes Sciences, 715 Sumter St.,

Columbia, SC 29208. Tel: 803-777-4715. E-mail:

maxwell@sccp.sc.edu

(Note: At time of submission, Breanne Martinez was affiliated with the South Carolina College of Pharmacy.) education disciplines including pharmacy, medical, nursing, and dentistry education. A variety of strategies and interventions to promote student self-awareness have been described in the healthcare education literature, including, mindfulness and metacognition, ${ }^{6}$ discussion groups, ${ }^{7}$ self-assessment tools, ${ }^{7}$ role-play, ${ }^{7,8}$ self-reflection, ${ }^{8}$ mentorship, ${ }^{9}$ and portfolio development. ${ }^{9}$ However, the optimal approach to increasing self-awareness or measuring changes in self-awareness in pharmacy education is yet to be determined.

A variety of definitions of self-awareness have been proposed in the educational, medical, and business literature. Common components of the definitions in the educational literature include knowledge of and attentiveness to personal behaviors, attitudes, needs, and emotions. ${ }^{10-12}$ However, structured or objective measurements of changes in self-awareness have not been routinely used in this arena. In the medical literature, patient self-awareness is defined and measured more objectively as the extent of concordance between patients' self-reported awareness and clinical ratings. ${ }^{13}$ Similarly, the business literature also approaches defining and measuring self-awareness more 


\section{American Journal of Pharmaceutical Education 2016; 80 (9) Article 148.}

objectively. In this context, self-awareness is defined as the agreement between an individual's self-perceptions and external perceptions about that individual. ${ }^{14}$ According to McCarthy and colleagues, "Self-awareness is a broader concept that focuses on the image that an individual has of $\mathrm{him} /$ herself and whether or not that image is accurate. .."15 Individuals with accurate self-perceptions generally have better outcomes and tend to be more successful from organizational and leadership performance perspective. ${ }^{14}$

McCarthy and colleagues also posit that the term "self-perception accuracy" is synonymous with the term "self-awareness" in the literature describing corporate career development and performance appraisal. ${ }^{15}$ Thus, self-awareness increases measurably when discrepancies between self-perceptions and external perceptions resolve. ${ }^{14}$ With this in mind, our study uses the Birkman Method assessment as an external benchmark against which students' self-perceptions are compared to assess for accuracy. Within this framework, changes in self-perception accuracy serve as indicators of changes in self-awareness. Using this more objective approach to self-awareness described in the medical and business literature enables evaluation of the impact of Birkman Method testing and training on pharmacy students' self-perception accuracy, and therefore, self-awareness.

The Birkman Method is a validated self-assessment tool that facilitates self-awareness, social awareness, and assists with career planning. ${ }^{16,17}$ It is a 298 -question selfassessment tool describing an individual's usual communication style and behaviors, communication and behavior styles under stress, needs from others, and interests. The instrument evaluates individuals' usual style and needs compared with others across 27 scales, including emotive orientation, social orientation, process orientation, and others. A complete listing of the 27 scales can be found in Appendix 1 .

Although no published studies describe use of the Birkman Method assessment in pharmacy education, a few studies describe its use in other educational and medical settings. In secondary education settings, studies describing use of the Birkman Method have demonstrated that personality traits and social perceptions of adolescents are significantly different from those in adults but that vocational interests in adolescents resemble those in adults. ${ }^{18}$ Significant differences exist between male and female secondary school administrators across some of the Birkman scales described in Appendix 1, identifying possible gender-related differences between usual, needs, and stress behaviors. ${ }^{19}$

At the graduate education level, significant associations between certain Birkman-identified dispositions and teaching styles have been observed in a sample of graduate-level student teachers. ${ }^{20}$ The Birkman Method has also been used to assess potential impacts of non- cognitive variables in medical school applicants on acceptance for admission. ${ }^{21}$ In medical settings, one health-system has initiated a corrective coaching program incorporating Birkman testing for physicians who demonstrate negative behavior patterns and has been deemed beneficial by hospital adminsitration. ${ }^{22}$ The Birkman Method also has been used as a constructive coaching tool in a leadership academy within a teaching hospital that trains physicians, nurses, and health-system administrators as fellows of this internal leadership development program. One outcome of this leadership fellow academy was that $57 \%$ of participants experienced career goal changes after completing the program. ${ }^{23}$

A variety of reports are generated from the Birkman Method assessment including a color-coded Lifestyle Grid, as seen in Figure 1. The Lifestyle Grid has 4 color quadrants, red, yellow, green, and blue. Individuals whose usual communication and behavior styles are mapped within the red quadrant are globally classified as expediters. According to the Birkman Method, these individuals would be anticipated to be direct communicators and task-oriented in their usual behaviors. Expediters typically focus on operations or production and they value tactical short-term goals, take action on objectives, and display a candid communication style. They are usually seen as hands-on, decisive, and forceful, but under stress may appear demanding, impatient, impulsive, or even detached. Individuals whose usual communication and behavior styles are mapped within the green quadrant are globally classified as communicators. These individuals are expected to be direct communicators and peopleoriented in their usual behavior.

Communicators typically focus on selling or promoting initiatives and are good at influencing or motivating people through active, ongoing communication. They are usually seen as persuasive, conversational, and energetic. However, under stress communicators may appear bossy, restless, or even pushy. The yellow quadrant is used to describe individuals with a propensity toward numbers and systems who tend to be indirect communicators with a usual orientation toward tasks and are classified as administrators. Administrators typically focus on coordinating processes or systems and are good with analyzing large amounts of data and speaking to the proven facts. They are usually seen as detailed, scheduled and structured, and may be perceived as change-averse. Under stress they may appear controlling or even stubborn.

Finally, the blue quadrant describes planners who are indirect communicators and are generally peopleoriented. Planners generally focus on strategy and innovation, operate with an idealistic outlook, and tend to value the welfare of people. They are usually seen as cautious, 


\section{American Journal of Pharmaceutical Education 2016; 80 (9) Article 148.}

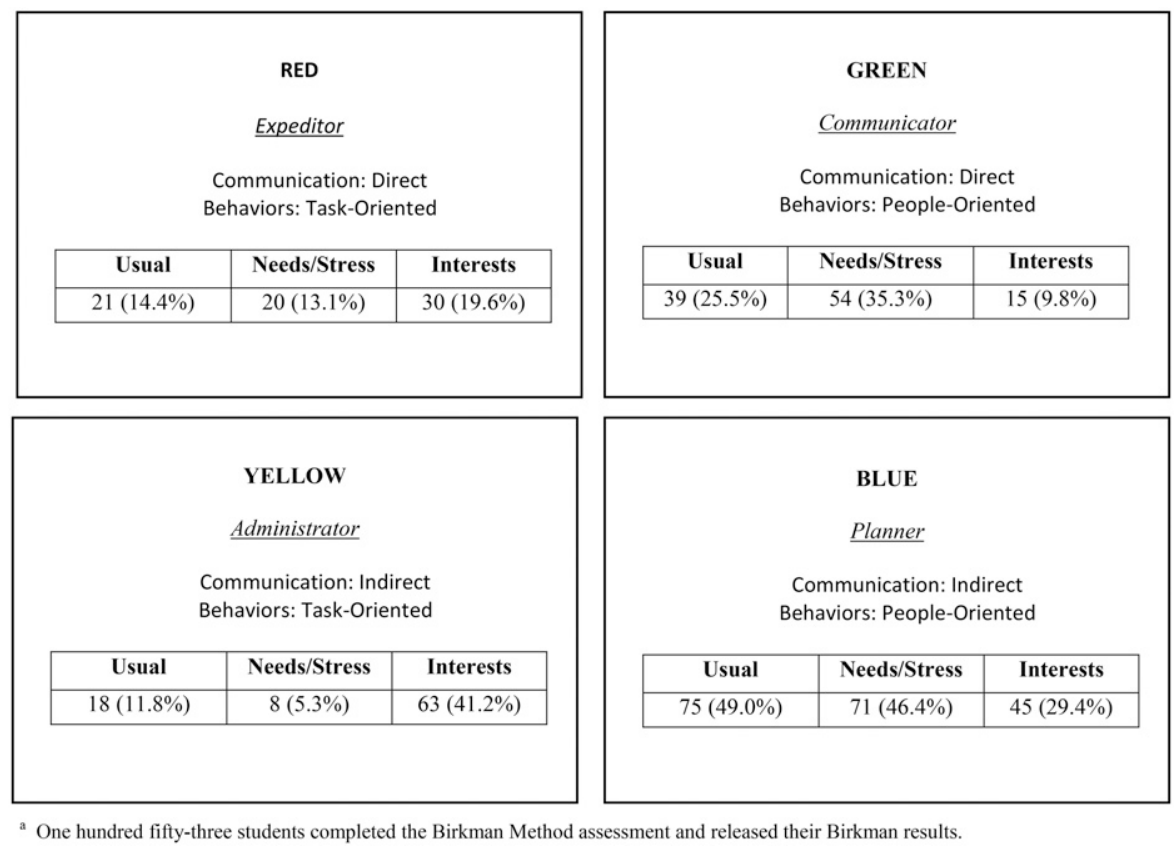

Figure 1. Number and Percentages of Student Birkman Types within the Quadrants of the Birkman Lifestyle Grid ${ }^{\mathrm{a}}$.

reflective, and soft-hearted. Under stress, planners may appear to be indecisive, overly sensitive and a free spirit. Individuals' interests are also mapped along the Birkman Lifestyle Grid continuum and a percentile ranking of interest alignment with broad occupational areas (eg, social services, scientific, numerical, clerical, mechanical, and others) is also provided. ${ }^{24}$

More than 2 million people have completed the Birkman Method assessment, which has been in use for approximately 50 years by 5,000 organizations globally, including a variety of corporate and academic institutions. ${ }^{25}$ One of the business schools affiliated with South Carolina College of Pharmacy has been using the Birkman Method assessment in their Master of Business Administration (MBA) program for several years. All students enrolled in the MBA program complete the assessment and participate in 40 hours of classroom lecture and facilitated learning exercises the week prior to the start of classes. A Birkman Method coach is on staff and available throughout the year to advise the students on the use of the Birkman Method and assist students in creating a resume to reflect their identified interests and behaviors. In addition, several MBA classes use the Birkman Method to form teams that create an environment for coaching opportunities and the development of high-performance teams. This program has reported an increase in 90-day graduate employment from $45 \%$ to $88 \%$ that is attributed, at least in part, to the use of the Birkman Method assessment. ${ }^{26}$

The reliability and validity of the Birkman Method instrument has been evaluated in depth. Test-retest reliability has been demonstrated across the 27 scales used within the 298-item assessment, with correlations ranging from 0.57 0.91 (Mean $=0.79)$. Internal consistency of the tool has been estimated using Cronbach's alpha across the scales (Range: 0.54 to 0.88 , Mean $=-0.73$ ). Additionally, Item Response Theory (IRT) reliability statistics assessed using a Rasch model have demonstrated that the various Birkman Method scales have sufficient precision to discriminate reliably between high percentages of individuals (Range: $58-95 \%$, Mean $=82.2 \%$ ) across the entire distribution of individual scores. The convergent construct validity of the Birkman Method has been evaluated against 7 other psychometric instruments, including the Myers-Briggs Type Indicator (MBTI). This evaluation demonstrated a strong correlation between some, but not all scales from the Birkman Method. ${ }^{27}$ The scales correlating with the MBTI are those that emphasize individual behaviors and communication styles rather than understanding of others' behaviors and communication styles. This is not surprising because understanding of others' behaviors and communication styles is of greater emphasis in approximately half of the Birkman Method scales.

Compared to MBTI, the Birkman Method contains 2 non-personality scales and 10 interest scales, which MBTI does not have. ${ }^{27}$ Additionally, information regarding analysis of usual behaviors, stress behaviors, needs, and interests is provided as a continuum measurement but can be easily compared to others along the Birkman Lifestyle Grid continuum. Conversely, MBTI does not provide a specific measurement of where the participant falls 


\section{American Journal of Pharmaceutical Education 2016; 80 (9) Article 148.}

within a range, but instead provides a categorization. ${ }^{28}$ The divergent construct validity of the Birkman Method instrument has also been evaluated against 7 other instruments including the Emotional Intelligence-International Personality Item Pool (EI-IPIP), revealing no significant relationships between them. This is thought to be due to EI-IPIP assessing internal cognitive status and abilities as opposed to emotions representing perceptions and personality in the Birkman Method instrument. ${ }^{27}$

Another commonly used psychometric instrument, the Clifton Strength Finder 2.0 (CSF) is a tool to identify the values and interests of the individual. Because the CSF measures only individualized parameters and does not also provide information that is likely to enable interpersonal application and relationship management, the Birkman Method may provide an additional benefit over this and other assessments. ${ }^{29}$

For these reasons, the Birkman Method assessment was selected for use as a co-curricular tool to promote professional development among students attending the South Carolina College of Pharmacy (SCCP). However, there are currently no published studies evaluating the Birkman Method in pharmacy education. This study evaluates the Birkman Method as a mechanism for promoting pharmacy student self-awareness. The specific aim of the study is to evaluate student self-confidence, self-perceptions, and self-awareness before and after completion of the Birkman Method assessment and training program offered at the South Carolina College of Pharmacy. Additionally, this study describes the Birkman type profile of a sample of pharmacy students at the end of the first year of the PharmD program.

\section{METHODS}

A co-curricular Birkman Method program was instituted on the two largest of three SCCP campuses and involved 191 PharmD students nearing completion of their first professional year. The program required students to complete the Birkman Method assessment in their free time, review their personalized results, and attend a 2-hour training session provided by a certified Birkman training consultant. To determine the impact of this program on self-awareness, the investigators generated a pre- and post-Birkman survey, in which students were asked to describe their self-confidence regarding selected elements of career path planning and their selfperceptions regarding behavioral and communication styles. The self-confidence portion of the survey instrument was mapped to the learning objectives from the Birkman Method training session. These questions included work environment preferences and elements of relationship management, such as ability to perceive others' needs during conflict or for coaching purposes.

The self-perception portion of the survey instrument was developed to mirror key Birkman Method results, including self-perceived usual behavior (people vs task oriented) and usual communication style (direct vs indirect), as well as self-perceived stress behavior (people vs task oriented) and stress communication style (direct vs indirect). The students were also asked to describe which behavior and communication style the student believed would prevent him or her from becoming stressed. The self-confidence questions are described in Table 1, the self-perception questions are included in Table 2, and the survey questions are provided in Appendix 2. The pre- and post-Birkman survey questions were identical except for the question addressing prior personality testing/coaching, which was included only on the preBirkman survey instrument, and the question addressing career interest changes which was included only on the post-Birkman survey instrument. Students also were asked to provide general demographic information. Prior

Table 1. Impact of Birkman Assessment and Training on Student Self-Confidence $(\mathrm{N}=114)^{\mathrm{a}}$

\begin{tabular}{|c|c|c|c|}
\hline Survey Questions & $\begin{array}{c}\text { Pre-Birkman } \\
\text { Score }\end{array}$ & $\begin{array}{l}\text { Post-Birkman } \\
\text { Score }\end{array}$ & $p$ \\
\hline $\begin{array}{l}\text { I am confident in my ability to accurately describe my interests and preferred } \\
\text { activities in work environments or other structured environments }\end{array}$ & 4.1 & 4.0 & 0.73 \\
\hline $\begin{array}{l}\text { I am confident in my ability to perceive what others need from me emotionally } \\
\text { or socially during a conflict }\end{array}$ & 4.0 & 3.6 & $<0.0001^{*}$ \\
\hline $\begin{array}{l}\text { I am confident that I can describe how others could tailor their coaching or } \\
\text { leadership style to make it most effective for me }\end{array}$ & 3.9 & 3.9 & 0.45 \\
\hline $\begin{array}{l}\text { I am confident that I can tailor my coaching or leadership style so it is most } \\
\text { effective for those who I coach or lead }\end{array}$ & 3.8 & 3.8 & 0.95 \\
\hline $\begin{array}{l}\text { I can describe (in detail) the type of work environment conditions that would } \\
\text { be most comfortable for me to work in }\end{array}$ & 4.3 & 4.3 & 0.86 \\
\hline
\end{tabular}

${ }^{a}$ One hundred fourteen students answered all pre- and post-survey self-confidence questions

*Indicates a statistically significant finding 


\section{American Journal of Pharmaceutical Education 2016; 80 (9) Article 148.}

Table 2. Impact of Birkman Assessment and Training on Doctor of Pharmacy Students' Self-Perception $(\mathrm{N}=111)^{\mathrm{a}}$

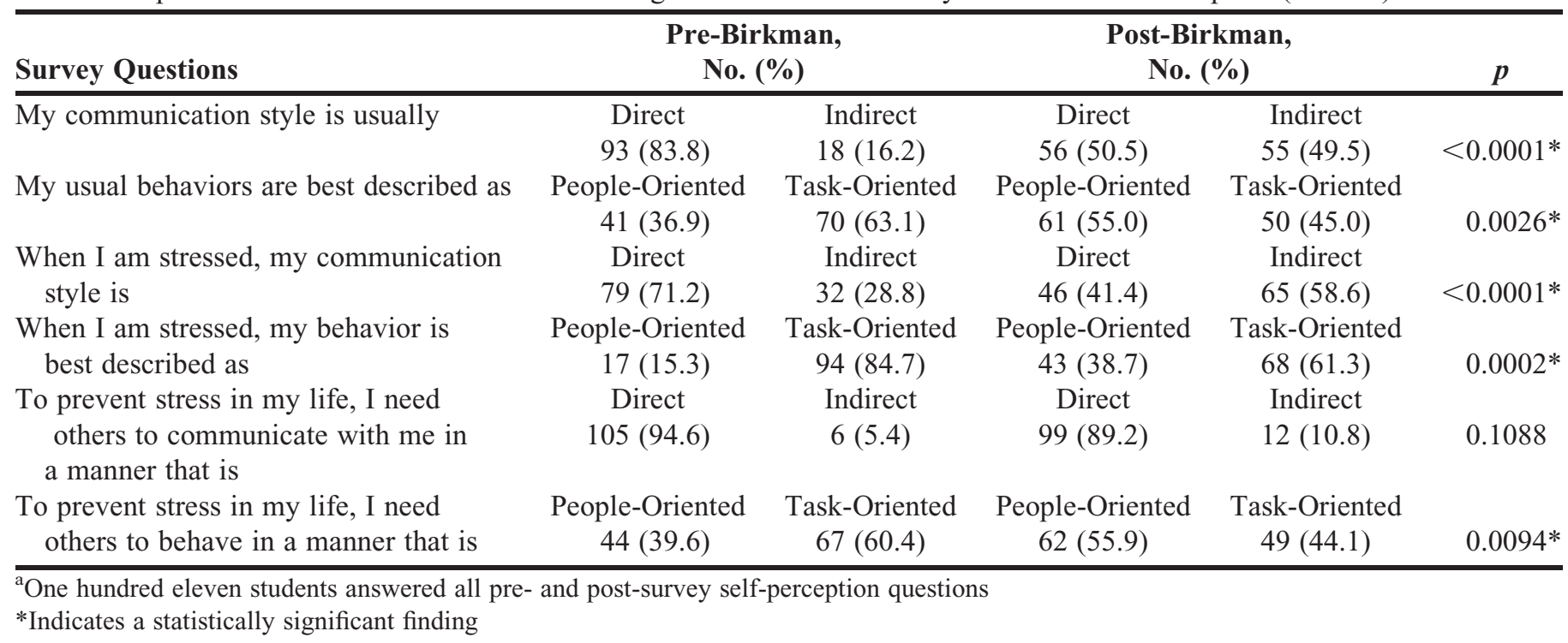

to use, the survey tools were internally peer-reviewed. The peer-review process involved distributing the survey tools to a small group of student and faculty members. These individuals were asked to complete the survey tool, assess for ease of use and clarity of content, and provide feedback prior to survey distribution. The internal consistency and reliability of these investigator-generated self-confidence survey questions was also evaluated by calculating Cronbach's alpha.

After approval of this study by the Institutional Review Board as exempt research, students involved in the Birkman Method program were invited to participate in the research study before completing the Birkman Method assessment. Within approximately 1 week of completing the pre-Birkman research survey, participating students completed the electronic Birkman Method assessment. Approximately 4 months later, each student received a $40+$ page report describing his or her Birkman type, including the usual behavior and communication style, stress/needs behavior and communication style, and interests. Students then participated in a 2-hour Birkman training session provided by a certified Birkman training consultant. The primary objectives of the training session included assistance with interpretation and application of the personalized Birkman report; identification of interests and preferred workstyle; explanation of the importance of self-awareness, relationships, and diverse opinions in building high-performance teams; identification of coaching tools to enhance conflict resolution and improve communication; and application of the information through participation in hands-on case studies.

Students were subsequently invited to complete the post-Birkman survey instrument. Students were asked to avoid referencing any Birkman report documents they may have had available while completing the post-Birkman survey to assess for comprehension and internalization of the Birkman type and basic information. The pre- and postBirkman survey tools were replicates of each other and both used a 5-point Likert scale, with the scale ranging from a score of $1=$ strongly disagree through $5=$ strongly agree. While surveys and Birkman Method assessment results data released by students for research purposes were necessarily identified upon submission to enable pairing of data, all data were coded and de-identified prior to analysis.

Using the actual Birkman types as a benchmark, accuracy of each study subject's pre- and post-Birkman survey results was quantified using an investigatorgenerated self-perception accuracy-scoring tool. This self-perception accuracy-scoring tool was developed by breaking down the specific components of the Birkman Method assessment results, including usual and stressed communication styles and needs as well as usual and stressed behavior styles and needs, and allocating 1 point for agreement of each of these components with student self-perceptions from the pre- and post-Birkman student self-perception survey. Higher scores indicate greater agreement between student self-perceptions and actual Birkman Method results.

The maximum self-perception accuracy score that could be assigned to any study subject was 6 , indicating a perfect match between students' self-perceptions and the Birkman Method assessment results, including style of usual communication, usual behavior, stress communication, stress behavior, and communication and behavioral needs from others. Actual Birkman Method type 


\section{American Journal of Pharmaceutical Education 2016; 80 (9) Article 148.}

results were used as a benchmark for the self-perception accuracy scoring tool because of the instrument's demonstrated reliability to discriminate between the different communication and behavioral styles across the range of possible responses. The self-perception accuracy scoring tool is described in Appendix 3.

Descriptive statistics were used to evaluate study subject demographics and Birkman results data. The preand post- Birkman Likert scale-based self-confidence data and pre- and post-Birkman self-perception accuracy scores were analyzed using the Wilcoxon signed rank test. McNemar's test was used to compare the paired categorical data describing student self-perceptions before and after the Birkman assessment. Pearson's correlation analysis was used to evaluate the relationships between study subjects' age and both pre- and post-Birkman self-awareness accuracy scores, age, and change in the self-perception accuracy score. The relationship between self-perception accuracy changes and self-confidence changes was also assessed using correlation analysis. Statistical analyses were performed using SAS for Windows software, Version 9.4 (SAS Institute Inc., Cary, North Carolina).

\section{RESULTS}

Of the 191 students invited to participate in this survey study, 181 participated to some degree (Figure 2). Among them, 158 students $(82.7 \%)$ completed the preBirkman survey and 146 students (76.4\%) completed the post-Birkman survey. Eleven pre-Birkman survey instruments were not included in the analysis because they did not have respondents' names and could not be linked to other data points. One hundred fourteen $(59.7 \%)$ students completed the entire self-confidence portion of both the pre- and post-Birkman surveys and 111 (58.1\%) students completed the self-awareness portion of both the pre- and post-Birkman surveys. To protect student privacy and confidentiality, Birkman types were only released to the research team for those students who had signed release forms. One hundred students (52.4\%) signed a Birkman type release, completed the pre-Birkman survey, and completed the post-Birkman survey; therefore, only their data were available for analysis in the self-perception accuracy assessment.

The average age of the 181 participants was 23.8 years (Table 3 ). The highest level of education completed by the majority $(52.2 \%)$ of respondents was high school; $43.3 \%$ had completed a bachelor's degree. This sample of students accurately represents the demographics of the 2 SCCP campuses surveyed. The most prevalent Birkman type in our sample of first-year pharmacy students was a blue usual (indirect) communication and (people-oriented) behavior

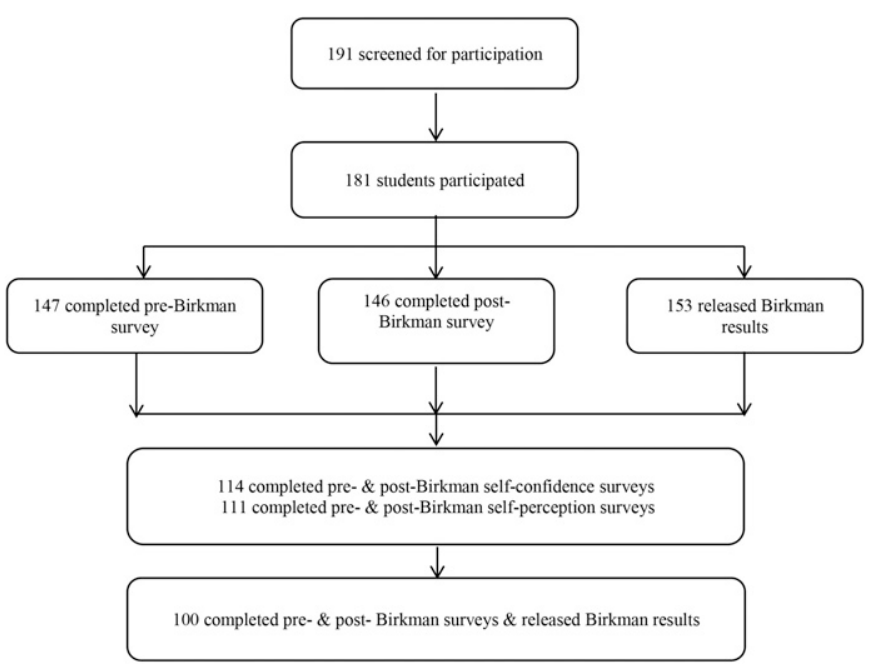

Figure 2. Study Participation Summary.

type (49\%), blue needs and stress (indirect) communication and (people-oriented) behavior type (46.4\%), and yellow (administrator) interest type (41.2\%).

There were significant changes from baseline in student self-perceptions after the Birkman assessment. As shown in Table 1, significant changes from baseline ( $p<0.05$ for all endpoints), were seen in self-perceived communication style (direct vs indirect) from baseline in both usual and stressed conditions, as well as in selfperceived usual and stress behavior styles (people-oriented vs task-oriented) from baseline. Response to the student self-perception survey question evaluating communication needs from others to prevent stress was the only survey finding that did not change significantly from baseline $(p=0.11)$. To assess the reliability of the internal consistency of this investigator-generated survey instrument, Cronbach's alpha was calculated for the confidence assessment questions of both the pre- (0.69) and post-Birkman (0.76) survey tools.

Seventy-four percent of respondents experienced an improvement in self-perception accuracy score from

Table 3. Baseline Characteristics of Study Participants $(\mathrm{N}=181)$

\begin{tabular}{lc}
\hline Baseline Characteristics & Response \\
\hline Age, y (Mean) & 23.8 \\
Gender, No. (\%) & \\
$\quad$ Male & $53(29.3)$ \\
Female & $128(70.7)$ \\
Highest level of education completed, No. (\%) & \\
High school diploma & $94(52.2)$ \\
Associate's degree & $1(0.6)$ \\
Bachelor's degree & $78(43.3)$ \\
Master's degree & $7(3.9)$ \\
\hline
\end{tabular}




\section{American Journal of Pharmaceutical Education 2016; 80 (9) Article 148.}

baseline. The mean self-perception accuracy score increased from a pre-Birkman baseline of 2.6 to 4.2 out of 6 possible points following Birkman testing and training. This improvement in self-awareness, as indicated by an increase in self-perception accuracy score from baseline was significant, with a mean increase of $1.6(95 \% \mathrm{CI}: 1.3-$ $1.9 ; p=<0.0001)$. Thus, we observed a large practical difference in self-perception accuracy, and therefore self-awareness post- vs pre-Birkman (Cohen's d=1.12).

Unlike self-awareness, student self-confidence did not significantly change from baseline after Birkman testing and training. The mean baseline self-confidence score was 4 out of 5 possible points. There was a significant decline from baseline in students' self-confidence in their ability to perceive what others need from them emotionally or socially during a conflict $(p<0.0001)$. All other selfconfidence parameters either declined in a non-significant manner or remained similar to baseline as shown in Table 2 .

A weak, non-significant, negative relationship between self-confidence changes and self-perception accuracy changes was found between the pre- and post-Birkman data $(\mathrm{r}=-0.06, p=0.56)$. Similarly, there was a weak, non-significant, negative relationship between age and self-perception accuracy at baseline $(\mathrm{r}=-0.11, p=0.26)$, and after completing Birkman testing and training $(\mathrm{r}=-0.06, p=0.59)$. Additionally, there was weak, non-significant positive correlation between age and change in self-perception accuracy score after completing Birkman testing and training $(r=0.06$, $p=0.55$ ).

\section{DISCUSSION}

Students experienced significant changes in selfperceptions and self-awareness, as indicated by significant increases in self-perception accuracy scoring following Birkman testing and training. An unexpected finding of the study was static or declining self-confidence following Birkman testing and training. Although increases in self-perception accuracy did not correlate significantly with decreases in self-confidence from a statistical standpoint, a negative relationship between these 2 variables was present. Thus, students' self-confidence decline from baseline may have been related to improvements in selfawareness. We believe that this decline may be explained by the brevity of the Birkman training session, which lasted only 2 hours.

This amount of training may have given students a more realistic opinion of their abilities in the realms addressed by the self-confidence questions, but may not have been intensive enough or longitudinally reinforced enough to correct any deficiencies. This explanation is supported by the fact that students' self-confidence in their ability to perceive what others need from them emotionally or socially during a conflict declined significantly after Birkman testing and training $(p<0.0001)$. Perceiving others' needs during conflict or relationship management requires high-level understanding and application of principles of self-awareness and others-awareness. This high-level skill probably cannot be mastered in a 2-hour training session. An alternate explanation for the decline in self-confidence from baseline may be the result of students having a high, and perhaps inflated, sense of selfconfidence at baseline.

The mean self-confidence score was 4 out of 5 possible points across all self-confidence questions at baseline compared to a mean score of 3.92 out of 5 after completing Birkman testing and training. The decline in student self-confidence also could be attributable to a combination of these factors. The inflated self-confidence levels may have been a consequence of the investigators' inability to blind the surveys to facilitate pairing of preand post-Birkman survey data and pairing of students' Birkman results with survey data for analysis, which is another limitation of this study.

In the absence of previously validated tools to measure the impact of the Birkman Method assessment on self-perceptions, self-confidence, or self-awareness, the most obvious limitation of our study is use of investigatorgenerated survey instruments to evaluate pharmacy student self-confidence and to assess accuracy of student self-awareness. However, the tools were internally peer reviewed prior to use and applied uniformly across the data set. Additionally, the Cronbach's alpha calculated for the confidence assessment approximated or exceeded 0.7 , so study investigators deemed the survey tool appropriate for determining the utility of the Birkman Method assessment tool in the context of our PharmD program. Because the Birkman Method assessment tool has undergone extensive reliability and validation procedures, the comparison of self-perception data from the investigatorgenerated self-perception survey questions to Birkman results appropriately benchmarks individuals' communication and behavior styles in both, the usual and stressed state, and also addresses needs and interests.

Before completing the post-survey, students received their Birkman Method report to enhance learning during the training sessions. Thus, the possibility cannot be ruled out that students referred to their Birkman Method report data while completing the post-Birkman survey; however, the study team anticipates that this would not have been a common occurrence. The research team attempted to limit this practice as much as possible by asking students not to reference the documents while completing the post-survey, and by monitoring the room as students were completing the post-survey. 


\section{American Journal of Pharmaceutical Education 2016; 80 (9) Article 148.}

This study is the first to evaluate use of the validated Birkman Method assessment in the context of pharmacy education. It demonstrates that a Birkman Method assessment and training program improves pharmacy student self-awareness, as indicated by significant increases in self-perception accuracy. Our findings contribute to the existing Birkman-related educational and medical literature by demonstrating the efficacy of the instrument for pharmacy co-curricular use to satisfy accreditation standard requirements pertaining to self-awareness. Thus, it should be added to the arsenal of options that pharmacy and other healthcare education programs consider when addressing educational outcomes related to self-awareness.

Future directions for Birkman-related research should include a variety of interventions to determine the full utility of the tool in pharmacy education. The impact of more intense and longitudinal Birkman training interventions on student self-confidence than the brief, 2-hour intervention described in this study should be assessed. Additionally, an evaluation of the impact of the Birkman assessment on group dynamics could inform and improve team assignment methods for team-based learning. Evaluating use of the Birkman Method assessment in faculty and preceptor development programs would also provide helpful information regarding the usefulness of the tool in academic pharmacy. Finally, the impact of Birkman Method testing and training on student career-path planning and job placement should also be considered.

\section{CONCLUSION}

Participation in the Birkman testing and training program resulted in significant changes in self-perceptions, significant improvements in self-perception accuracy, and therefore, self-awareness improvement from baseline. The results of our study indicate that the Birkman Method assessment represents a viable option for improving student self-awareness, and represents a tool that colleges of pharmacy could consider using to achieve ACPE 2016 Accreditation Standard 4 affective domain elements while educating pharmacy students.

\section{ACKNOWLEDGMENTS}

Funding for student Birkman Method testing and training was provided by the Kennedy Pharmacy Innovation Center at the University of South Carolina.

\section{REFERENCES}

1. Accreditation Council for Pharmacy Education. Accreditation standards and key elements for the professional program in pharmacy leading to the doctor of pharmacy degree. Standards 2016. https://
www.acpe-accredit.org/pdf/Standards2016FINAL.pdf. Accessed July 25, 2015.

2. Romanelli F, Cain F, Smith KM. Emotional intelligence as a predictor of academic and/or professional success. Am J Pharm Educ. 2006;70(3):Article 69.

3. Nelson MH, Fierke KK, Sucher BJ, Janke KK. Including emotional intelligence in pharmacy curricula to help achieve CAPE outcomes. Am J Pharm Educ. 2015;79(4):Article 48.

4. Stoller JK, Taylor CA, Farver CF. Emotional intelligence competencies provide a developmental curriculum for medical training. Med Teach. 2013;35(3):243-247.

5. Akerjordet K, Severinsson E. Emotional intelligence: a review of the literature with specific focus on empirical and epistemological perspectives. J Clin Nurs. 2007;16(8):1405-1416.

6. Lovas JG, Lovas DA, Lovas PM. Mindfulness and professionalism in dentistry. J Dent Educ. 2008;72(9):998-1009. 7. Novack DH, Epstein RM, Paulsen RH. Toward creating physician-healers: fostering medical students' self-awareness, personal growth, and well-being. Acad Med. 1999;74(5):516-520. 8. Latif DA. Using emotional intelligence in the planning and implementation of a management skills course. Pharm Educ. 2004;4 (2):81-89.

9. McMullan M. Using portfolios for clinical practice learning and assessment: the pre-registration nursing student's perspective. Nurse Educ Today. 2008;28(7):873-879.

10. Benbassat J, Baumal R. Enhancing self-awareness in medical students: an overview of teaching approaches. Acad Med. 2005;80 (2):156-161.

11. Saunders PA, Tractenberg RE, Chaterji R, et al. Promoting self-awareness and reflection through an experiential mind-body skills course for first year medical students. Med Teach. 2007; 29(8):778-784.

12. Dobie S. Viewpoint: reflections on a well-traveled path: selfawareness, mindful practice, and relationship-centered care as foundations for medical education. Acad Med. 2007;82(4):422-427. 13. Kelley E, Sullivan C, Loughlin JK, et al. Self-awareness and neurobehavioral outcomes, 5 years or more after moderate to severe brain injury. J Head Trauma Rehabil. 2014;29(2)147-152.

14. Yammarino FJ, Atwater LE. Understanding self-perception accuracy: implications for human resource management. Human Res Manage. 1993;32(2-3):231-247.

15. McCarthy AM, Garavan TN. Developing self-awareness in the managerial career development process: the value of 360-degree feedback and the MBTI $J$ Euro Ind Train. 1999;23(9):437-445. 16. Birkman RW, Elizondo F, Lee LG, Wadlington PL, Zamzow MW. The Birkman Method Manual. Houston, TX: Birkman International, Inc.; 2008

17. Birkman in my personal life. Birkman International Inc. https:// www.birkman.com/help/personal. Accessed July 25, 2015.

18. Wadlington E, Elizondo F, Wadlington P. Working with adolescents more productively. Acad Exch Quarterly. 2012;16(2):1-7. 19. Johnson S, Busch S, Slate JR. Leadership behaviors of school administrators: do men and women differ? http://cnx.org/contents/ 2f07aff9-c03a-40bb-8d39-59c37c239ccc@1/Leadership-Behaviorsof-School.pdf. Accessed November 25, 2015.

20. Wadlington E, Wadlington P. Teacher dispositions: implications for teacher education. Child Educ. 2011;87(5):323-326.

21. Dresden JH, Collins F, Roessler R. Cognitive and non-cognitive characteristics of minority medical school applicants. J Natl Med Assoc. 1975;67(4):321-323. 


\section{American Journal of Pharmaceutical Education 2016; 80 (9) Article 148.}

22. Lazoritz S. Coaching for insight: a tool for dealing with disruptive physician behavior. Physician Exec. 2008;34(1):28-31. 23. Korschun HW, Redding D, Teal GL, Johns MM. Realizing the vision of leadership development in an academic health center: the Woodruff Leadership Academy. Acad Med. 2007;82(3)264-271.

24. Fink SB, Capparell S. The Birkman Method: Your Personality at Work. San Francisco, CA: John Wiley \& Sons, Inc.; 2013:25-71.

25. Behavior assessment improves workplace performance. http:// www.birkman.com/images/uploads/BehavioralAssessmentImproves Workplace Performance.pdf. Accessed July 25, 2015.

26. Academic applications of the Birkman Method in colleges and universities. Birkman International Inc. www.birkman.com/images/ uploads/WP_University-Applications.pdf. Accessed July 25, 2015.
27. Birkman RW, Elizondo F, Lee LG, Wadlington P L, Zamzow MW. The Birkman Method Manual. Houston, TX: Birkman International, Inc.; 2008:145-193.

28. Wadlington P. A comparison between the Birkman Method and the Myers-Briggs Type Indicator. Birkman International Inc. https:// www.birkman.com/news/view/a-comparison-between-the-birkmanmethod-and-the-myers-briggs-type-indicator. Accessed November 25, 2015.

29. Wadlington P. A comparison between the Birkman method and the Clifton Strength Finder 2.0. Birkman International Inc. https://www. birkman.com/news/view/a-comparison-between-the-birkman-methodand-the-clifton-strengthsfinder-2.0. Accessed November 25, 2015.

Appendix 1. Birkman Method Scales

\begin{tabular}{ll}
\hline Usual Scales & \multicolumn{1}{c}{ Needs Scales } \\
\hline Usual Emotive Orientation & Emotive Orientation Needs \\
Usual Social Orientation & Social Orientation Needs \\
Usual Process Orientation & Process Orientation Needs \\
Usual Control Orientation & Control Orientation Needs \\
Usual Change Orientation & Change Orientation Needs \\
Usual Activity Preference & Activity Preference Needs \\
Usual Empathy Preference & Empathy Preference Needs \\
Usual Thought Preference & Thought Preference Needs \\
Usual Communication & Communication Preference \\
Preference & Needs \\
Usual Interaction Preference & Interaction Preference Needs \\
Usual Incentive Preference & Incentive Preference Needs \\
Usual Authority Preference & Authority Preference Needs \\
Usual Personal Autonomy & Personal Autonomy Needs \\
\hline
\end{tabular}

Perspective Alignment 


\section{American Journal of Pharmaceutical Education 2016; 80 (9) Article 148.}

Appendix 2. Student Survey Questions

Name:

Please use the following Likert Scale to complete the survey:

$1=$ strongly disagree, $2=$ disagree, $3=$ neutral, $4=$ agree, and $5=$ strongly agree

Attitudes and Abilities Assessment

1. It is important for pharmacy students to undergo testing to describe their communication styles, interests, and behaviors in usual situations and stressful situations

2. I am confident in my ability to accurately describe my interests and preferred activities in work environments or other structured environments

3. I am confident in my ability to perceive what others need from me emotionally or socially during a conflict

4. I am confident that I can describe how others could tailor their coaching or leadership style to make it most effective for me

5. I am confident that I can tailor my coaching or leadership style so it is most effective for those who I coach or lead

6. I can describe (in detail) the type of work environment conditions that would be most comfortable for me to work in

\section{Self-Awareness Assessment}

Please circle ONLY ONE option for each of the next 6 questions:

7. My communication style is usually

Direct Indirect

8. My usual behaviors are best described as

Task-Oriented People-Oriented

9. When I am stressed, my communication style is

Direct Indirect

10. When I am stressed, my behavior is best described as

Task-Oriented People-Oriented

11. To prevent stress in my life, I need others to communicate with me in a manner that is

Direct Indirect

12. To prevent stress in my life, I need others to behave in a manner that is

Task-Oriented People-Oriented

Demographics

Gender: $\square$ Male $\square$ Female

Age:

Highest Level of Education Already Completed:

$\square$ High School Diploma $\square$ Bachelor's Degree $\square$ Master's Degree

Current Pharmacy Practice Area Interest:

$\square$ Community $\square$ Hospital $\square$ Clinical $\square$ Administration

$\square$ Other:

Prior Personality Testing/Coaching

$\square$ I have never participated in personality testing/coaching

$\square$ I have participated in the following personality testing/coaching program previously: 
American Journal of Pharmaceutical Education 2016; 80 (9) Article 148.

\section{Career Interest Changes}

$\square$ My practice area interest has NOT changed since I participated in Birkman testing

$\square$ My practice area interest has changed as a result of Birkman testing

$\square$ My practice area interest changed since Birkman testing, but NOT because of testing

Appendix 3. Self-Perception Accuracy Scoring Tool

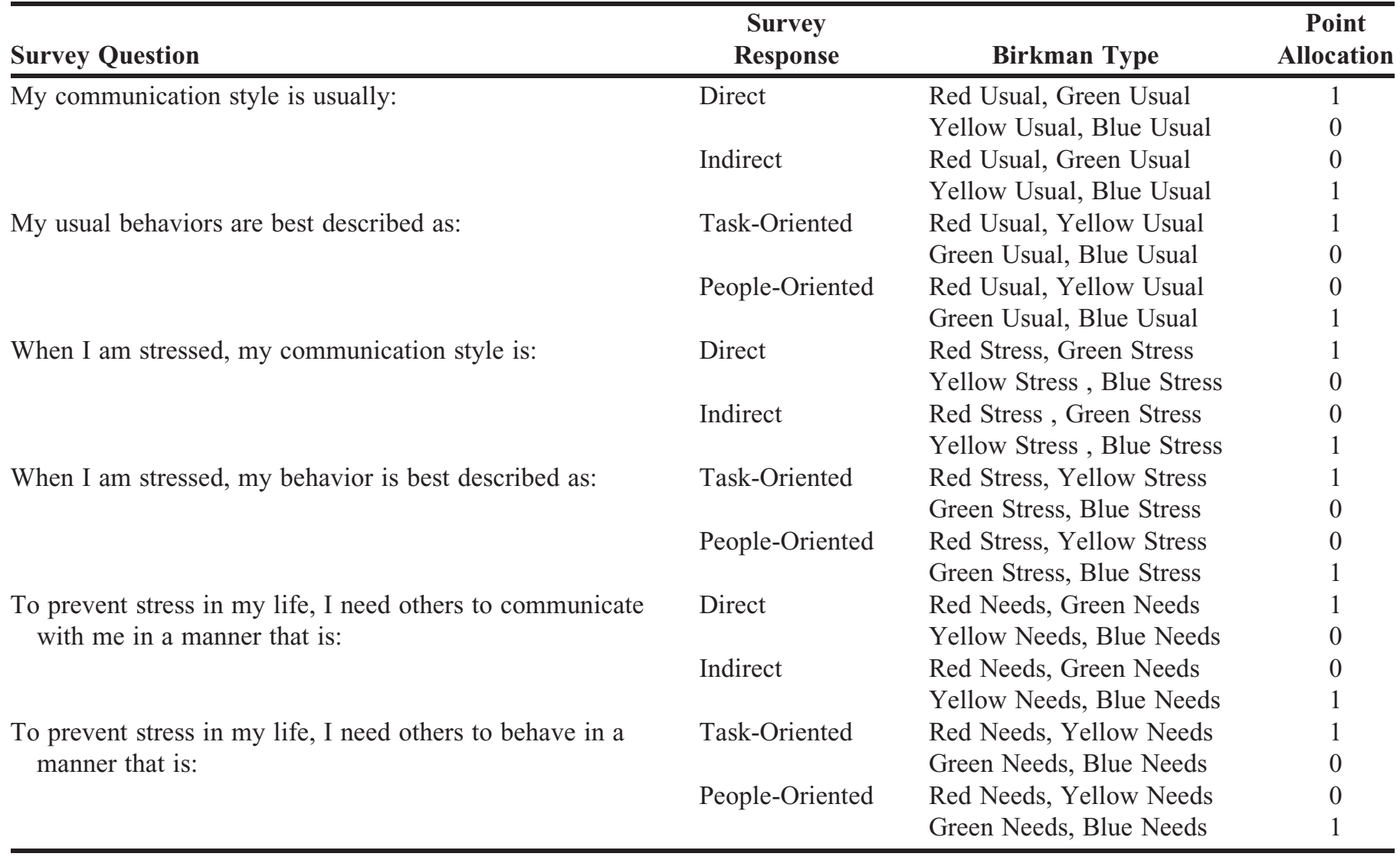

